Original article

\title{
Anti-inflammatory and anti-nociceptive effects of strontium ranelate on the zymosan-induced temporomandibular joint inflammatory hypernociception in rats depend on TNF- $\alpha$ inhibition
}

\author{
Sheila Moreira Alves ${ }^{a}$, Susana Capistrano Abreu ${ }^{a}$, Jonas Cavalcante Lemos ${ }^{a}$, \\ Francisco Isaac Fernandes Gomes ${ }^{\mathrm{a}}$, Shirley Moreira Alves ${ }^{\mathrm{a}}$, Danielle Rocha do Val ${ }^{\mathrm{b}}$, \\ Raul Sousa Freitas ${ }^{a}$, Karuza Maria Alves Pereira ${ }^{a}$, Vicente de Paulo Teixeira Pinto ${ }^{a}$, \\ Gerly Anne de Castro Brito ${ }^{c}$, Mirna Marques Bezerra ${ }^{a}$, Gerardo Cristino-Filho ${ }^{a}$, \\ Hellíada Vasconcelos Chaves ${ }^{\mathrm{a}, *}$ \\ a Federal University of Ceará, Avenida Comandante Maurocélio Rocha Pontes, 100 Derby, CEP: 62.042-280, Sobral, Ceará, Brazil \\ ${ }^{\mathrm{b}}$ Northeast Biotechnology Network (Renorbio), Federal University of Pernambuco, Av. Prof. Moraes Rego, 1235 Cidade Universitária, CEP: 50670-901, Recife, \\ Pernambuco, Brazil \\ ' Department of Morphology, Federal University of Ceará, Rua Delmiro de Farias, Porangabussu, CEP: 60440-261, Fortaleza, Ceará, Brazil
}

\section{A R T I C L E I N F O}

\section{Article history:}

Received 2 July 2016

Received in revised form 24 January 2017

Accepted 10 March 2017

Available online 12 March 2017

\section{Keywords:}

Temporomandibular joint

Arthritis

Strontium ranelate

TNF- $\alpha$

\begin{abstract}
A B S T R A C T
Background: Temporomandibular joint (TMJ) disorders show inflammatory components, heavily impacting on quality of life. Strontium ranelate has previously shown anti-inflammatory and antinociceptive effects on other experimental inflammatory pain models. Thus, we aim to investigate the strontium ranelate efficacy in reducing the zymosan-induced inflammatory hypernociception in the TMJ of rats by evaluating the TNF- $\alpha$, IL-1 $\beta$, and hemeoxygenase-1 (HO-1) involvement. Methods: Wistar rats were treated with strontium ranelate $(0.5,5$ or $50 \mathrm{mg} / \mathrm{kg}$, per os $) 1 \mathrm{~h}$ before zymosan injection (iart). Mechanical threshold was assessed by Von Frey test and synovial lavage was collected for leukocyte counting and myeloperoxidase measurement, joint tissue and trigeminal ganglion were excised for histopathological analysis (H\&E) and TNF- $\alpha / \mathrm{IL}-1 \beta$ levels dosage (ELISA). Moreover, rats were pre-treated with ZnPP-IX (3 mg/kg, sc), a specific HO-1 inhibitor, before strontium ranelate administration $(0.5 \mathrm{mg} / \mathrm{kg}$, per os), and Evans Blue $(5 \mathrm{mg} / \mathrm{kg}$, iv) was administered to assess plasma extravasation. Pre-treatment with indomethacin $(5 \mathrm{mg} / \mathrm{kg}, s c)$ was used as positive control while the sham group received $0.9 \%$ sterile saline (per os and iart).

Results: Strontium ranelate did not reduce leukocyte counting, myeloperoxidase activity, Evans Blue extravasation, IL- $1 \beta$ levels, and TNF- $\alpha /$ IL-1 $\beta$ immunolabeling; but it increased the nociceptive threshold and reduced TNF- $\alpha$ levels. Additionally, HO- 1 inhibition did not change the strontium ranelate effects. Conclusion: Strontium ranelate may achieve its antinociceptive effects through the reduction of TNF- $\alpha$ levels in the trigeminal ganglion, but not suppressing IL-1 $\beta$ expression nor inducing the HO- 1 pathway. (c) 2017 Institute of Pharmacology, Polish Academy of Sciences. Published by Elsevier Sp. z o.o. All rights
\end{abstract} reserved.

\footnotetext{
* Corresponding author.

E-mail addresses: eishyla2010@hotmail.com (S.M. Alves),

suzanact@hotmail.com (S.C. Abreu), jonas_cavalcante_@hotmail.com (J.C. Lemos), isaac.odonto@hotmail.com (F.I.F. Gomes), shirley_sma31@yahoo.com.br (S.M. Alves), danielleval@hotmail.com (D.R. do Val),raul.sf2@gmail.com (R.S. Freitas), karuzaalves@yahoo.com.br (K.M.A. Pereira), pintovicente@gmail.com (V. de Paulo Teixeira Pinto), gerlybrito@hotmail.com (G.A. de Castro Brito), mirnabrayner@gmail.com (M.M. Bezerra),gerardocristino@uol.com.br (G. Cristino-Filho), helliadachaves@yahoo.com.br (H.V. Chaves).
}

\section{Introduction}

The pathogenesis of temporomandibular joint (TMJ) disorders still remains unclear even with the remarkable progress already made towards the elucidation of their pathogenesis. Experimental models that allow the investigation of the inflammatory pain related to these disorders are of great clinical relevance and our group developed an experimental model of zymosan-induced arthritis in rats. Zymosan is a yeast cell-derived polysaccharide that 
produces a severe and erosive synovitis along with inflammatory pain in animal models of knee arthritis [1-3].

Inflammatory stimuli cause mechanical hypernociception by a defined sequential release of cytokines within inflamed joints by many cells such as tumor necrosis factor- $\alpha$ (TNF- $\alpha)$ and interleukin-1 $\beta$ [4]. TNF- $\alpha$ and IL-1 $\beta$ are highly expressed in the joints affected by TMJ disorders. Many studies showed considerable levels of both in the synovial fluid of patients suffering from this condition $[5,6]$. Furthermore, studies demonstrated that heme oxygenase - 1 (HO-1) exerts an antioxidant role and its induction would lead to negative feedback for cell activation and production of inflammatory mediators [7-9].

Strontium ranelate (Sran) $\{\sim 5$-[bis (carboxy-methyl) amino]-2carboxy-4-cyano-3-thiophen-acetic acid distrontium salt is a compound with two stable strontium atoms and ranelic acid. It affects the bone turnover and it is an orally active treatment which decreases the risk of vertebral and hip fractures in osteoporotic women [10,11]. Although its mechanism of action is not fully understood, this drug may possess analgesic effects [12]. Recent studies showed that strontium ranelate had a protective effect in experimental osteoarthritis [13] and it promoted analgesia in arthritic rats, which was associated to inhibition of the release of inflammatory cytokines into inflamed joints [14].

Thus, the present study attempts to investigate the unexplored anti-nociceptive and anti-inflammatory effects of strontium ranelate on the zymosan-induced inflammatory hypernociception in the TMJ of rats by evaluating the IL- $1 \beta$ and TNF- $\alpha$ levels after strontium ranelate treatment. Further, we aim to determine whether strontium ranelate effects on this experimental model of arthritis would depend on HO-1 pathway integrity as our previous results showed that HO-1 pathway inhibition is associated with increased inflammatory responses [8].
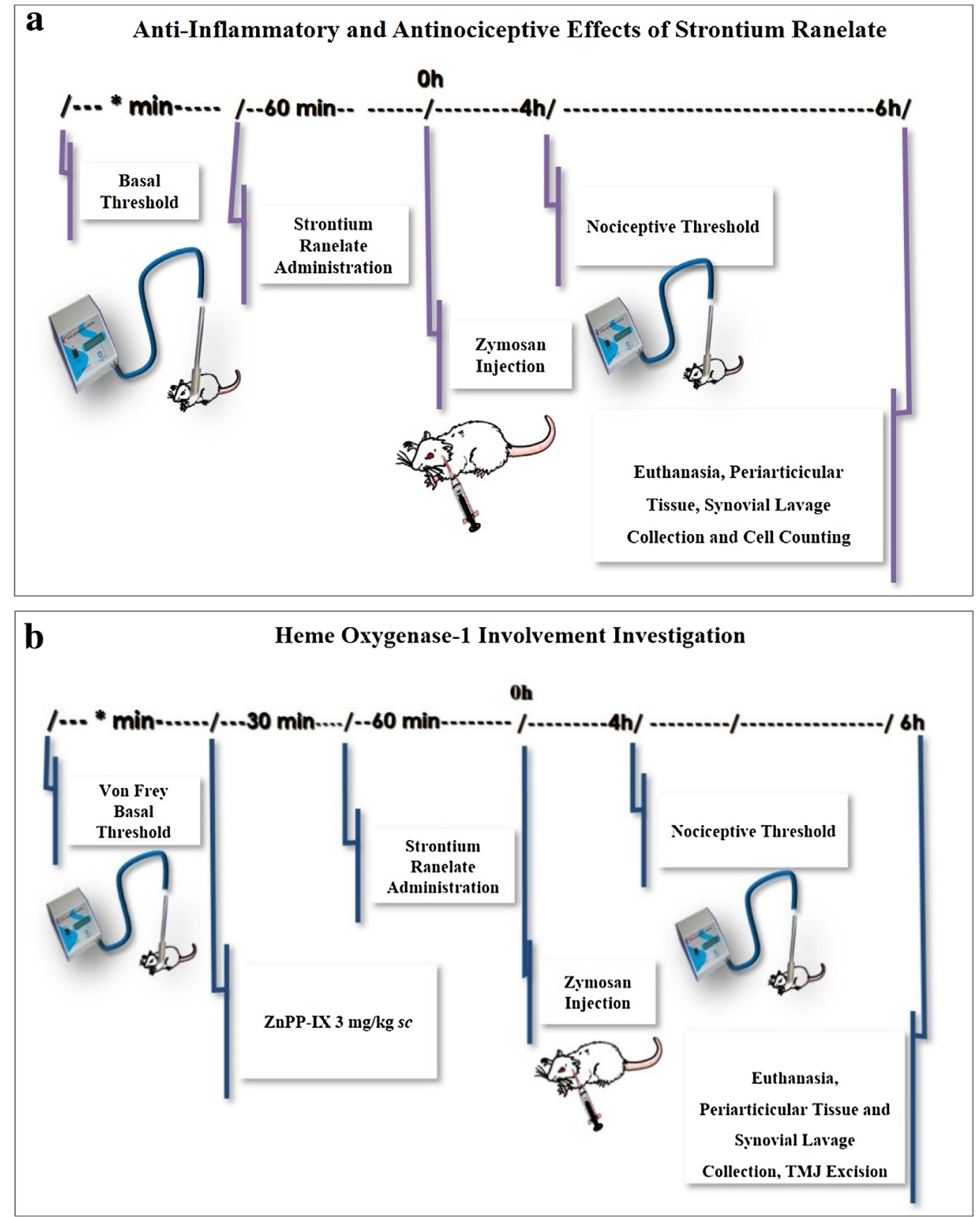

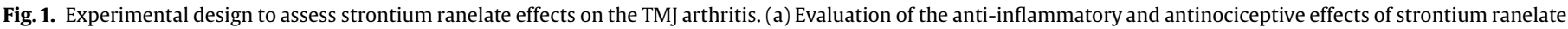

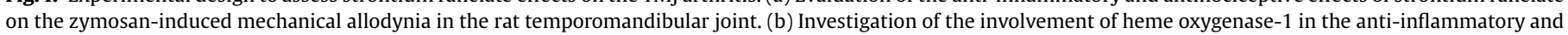
antinociceptive effects of strontium ranelate on the zymosan-induced mechanical allodynia in the rat temporomandibular joint. 


\section{Materials and methods}

Animals

Male Wistar rats ( $\mathrm{n}=6$ per group; $160-220 \mathrm{~g}$ ) were housed in standard plastic cages, they had access to food and water ad libitum and were maintained in a temperature-controlled room $\left(23 \pm 2^{\circ} \mathrm{C}\right)$ with a 12/12-h light-dark cycle. This study was conducted in accordance with the local Institutional Animal Care and with the approval of the local ethical committee (registration number 54/ 12 ) and we designed it to reduce animal suffering and the number of animals.

\section{Zymosan-induced inflammatory hypernociception}

To induce the inflammatory hypernociception, rats were anesthetized with inhaled isoflurane (4\%) and received intraarticular (iart) injection of zymosan $(2 \mathrm{mg} ; 40 \mu \mathrm{L})$ dissolved in sterile saline into the left TMJ using a 30-gauge needle. Sham animals received saline solution (per os) before zymosan or saline solution injections. The TMJ skin was shaved, the postero-inferior border of the zygomatic arch was located, and the needle was inserted in a position inferior to this point until the needle contacted the condyle, which was verified by the movement of the mandible and the puncture of the needle into the joint space was confirmed by the loss of resistance. Gentle aspiration ruled out intravascular injection, after which zymosan or saline solution were injected. As previously shown by our group [1] the zymosaninduced inflammatory hypernociception is maximal at $4 \mathrm{~h}$ of arthritis while polymorphonuclear cell influx peaks after $6 \mathrm{~h}$. Thus, we used these time points to assess the following parameters: head withdrawal threshold, total cell counting, and myeloperoxidase activity.

\section{Mechanical threshold evaluation}

Inflammatory hypernociception in the TMJ was evaluated by measuring the threshold of force needed to be applied to the TMJ region until the head withdrawal occurred. The measurements were performed by a blinded examiner who used a digital device (Insight, Brazil) that consisted of a rigid filament linked to an electronic device - automatic Von Frey anesthesiometer, which in turn measures the response threshold in grams $(\mathrm{g})$ when the filament is applied to the surface of the tested region [15]. The facial areas to be tested around the TMJ were shaved before the experimental procedure and the animals were placed in individual plastic cages $45 \mathrm{~min}$ before the tests. The animals underwent conditioning sessions in the testing room for 4 consecutive days. On day five, the basal force threshold value was recorded three times before and $4 \mathrm{~h}$ after the intra-articular injections of either zymosan or vehicle. Then, we measured the inflammatory hypernociception of the zymosan-group animals and treated controls. The applied mechanical stimuli were innocuous in control animals.

\section{Pharmacological modulation}

Strontium ranelate (PROTOS ${ }^{\circledR} 2 \mathrm{~g}$, Les Laboratoires Servier Industry, 45520 Gidy, France) $(0.5,5$ or $50 \mathrm{mg} / \mathrm{kg}$, per os) was administered one hour prior to zymosan injection (iart). Food was removed $1 \mathrm{~h}$ before the treatment in order to avoid any changes in the pharmacokinetic profile of strontium ranelate (Fig. 1a). Data validation was achieved by using a positive control group that was pre-treated with indomethacin $(5 \mathrm{mg} / \mathrm{kg}, s c) 1 \mathrm{~h}$ before zymosan injection. Sham group received (per os and iart) $0.9 \%$ sterile saline.
To analyze the possible effect of HO-1 pathway on anti-nociceptive and anti-inflammatory efficacy of strontium ranelate, animals were pre-treated $(s c)$ with ZnPP IX (3 mg/kg), a specific HO-1 inhibitor, followed by an injection (per os) of strontium ranelate $(0.5 \mathrm{mg} / \mathrm{kg}) 30 \mathrm{~min}$ later (Fig. 1b). After $1 \mathrm{~h}$, intra-articular zymosan-injection was performed and at the 4th hour, inflammatory hypernociception in the TMJ was evaluated.

\section{Synovial Lavage Collection, Cell Counting and Myeloperoxidase Activity Assessment}

Six hours after zymosan injections, the rats were sacrificed under anesthesia and exsanguinated. The superficial tissues were dissected and the TMJ cavity was washed two times to collect the synovial fluid by the pumping and aspiration technique using $0.05 \mathrm{~mL}$ of EDTA ( $1.77 \mathrm{mg}$ EDTA/1 mL PBS). The total number of white cells in the synovial lavage was counted using a Neubauer chamber. MPO activity assay measurement was described by Bradley et al. and it was conducted on the collected synovial lavage which was centrifuged at $4500 \mathrm{rpm}$ for $12 \mathrm{~min}$ at $4^{\circ} \mathrm{C}$. MPO activity was assayed by measuring the change in absorbance at $450 \mathrm{~nm}$ using o-dianisidine dihydrochloride and $1 \%$ hydrogen peroxide. The results are reported as the MPO units/joint fluid and a unit of MPO activity was defined as the conversion of a $\mu \mathrm{mol}$ of hydrogen peroxide to water in $1 \mathrm{~min}$ at $22^{\circ} \mathrm{C}$.

\section{Evans blue extravasation assay}

Strontium ranelate $(0.5 \mathrm{mg} / \mathrm{kg}$, per os $)$ was administered $1 \mathrm{~h}$ prior to zymosan injection. Thirty minutes before euthanasia, Evans Blue $(5 \mathrm{mg} / \mathrm{kg}, i \mathrm{v})$ was then injected to assess plasma extravasation. After its excision, the periarticular tissue was weighed, immersed into formamide solution $(1 \mathrm{~mL})$, and placed into water bath $\left(60^{\circ} \mathrm{C}\right)$ overnight. The resulting supernatant was collected and the absorbance was read at $620 \mathrm{~nm}$ using a spectrophotometer. The concentration was determined by comparison with a standard curve of Evans blue dye in the extraction solution and the amount of Evans blue dye $(\mu \mathrm{g})$ was then calculated per $\mathrm{mL}$ of exudate [16].

\section{Histopathological analysis}

The TMJ was excised six hours after the induction of the inflammatory hypernociception. The specimens were fixed in $10 \%$ neutral buffered formalin for $24 \mathrm{~h}$, demineralized in 10\% EDTA for 7 days, embedded in paraffin, and sectioned along the long axis of the TMJ. Sections of $5 \mu \mathrm{m}$, including the condyle, the articular cartilage, the articular disc, the synovial membrane, the periarticular tissue, and the skeletal muscle were evaluated under light microscopy $(400 \times)$. The specimens were prepared for routine hematoxylin-eosin (H\&E) staining and histological analysis considered a 0-4 score based on the following parameters: cell influx into the synovial membrane, cell influx into the connective tissue and the skeletal muscle of the periarticular tissue, and synovial membrane thickness.

\section{Immunohistochemistry}

Immunohistochemistry for TNF- $\alpha$ and IL-1 $\beta$ was performed using the streptavidin-biotin (Labeled Streptavidin Biotin - LSAB) method in formalin-fixed, paraffin-embedded tissue sections ( $5 \mu \mathrm{m}$ thickness), mounted on glass slides prepared with an organosilane-based adhesive (3-aminopropyltriethoxysilane, Sigma Chemical $\mathrm{Co}^{\circledR}$, St Louis, MO, USA). The sections underwent 2 baths in xylol for ten minutes each one. They were after immersed 
three times into alcohol at $100 \%$ concentration, and washed in distilled water.

Antigen recovery was performed with citrate ( $\mathrm{pH} 6.0 ; 30 \mathrm{~min}$; $99^{\circ} \mathrm{C}$ ). After returning to ambient temperature, the sections were immersed into a $3 \%$ hydrogen peroxide blocking solution for $10 \mathrm{~min}$. The sections were then incubated overnight $\left(4^{\circ} \mathrm{C}\right)$ with a primary rabbit anti-TNF- $\alpha$ and anti- IL-1 $\beta$ antibody $\left(A B C A M{ }^{\circledR}\right.$, England, UK), at the dilution of 1:200, and washed with PBS solution.

The samples were incubated with the secondary antibody LSAB Kit for $10 \mathrm{~min}$ at ambient temperature. Next, incubation was performed in a chromogen solution prepared with 3,3' diaminobenzidine (DAB) $\left(\mathrm{DAKO}^{\circledR}\right.$, Carpentaria, CA, USA), for $10 \mathrm{~min}$ in a dark chamber. Afterwards, the specimens were washed into running water and then into distilled water. Counter-staining was performed with hematoxylin, and afterwards the specimens were dehydrated in alcohol and diaphanized in xylol. Finally, they were mounted on glass slides. The negative control sections were performed excluding the application of the primary antibody. The parameter of positivity for the immunohistochemical marking of the antigen in all the specimens included in the sample consisted of the cells that exhibited brown staining in their cytoplasm irrespective of the intensity of the immunomarking.

\section{TNF- $\alpha$ and IL- $1 \beta$ ELISA assays}

The TMJ tissue and the trigeminal ganglion were excised $6 \mathrm{~h}$ after the zymosan-injection in rats and were homogenized in a solution of RIPA Lysis Buffer System (Santa Cruz Biotechnology, USA). The samples were centrifuged at $10000 \mathrm{rpm}$ for $15 \mathrm{~min}$ at $4{ }^{\circ} \mathrm{C}$. The supernatants were stored at $-80 \mathrm{C}$ for posterior analysis to evaluate the protein levels of TNF- $\alpha$ and IL-1 $\beta$ in the TMJ tissue and the trigeminal ganglion. The cytokine levels were quantified by the following kits: TNF- $\alpha$-Rat TNF-alpha/TNFSF1A Quantikine ELISA Kit (R\&D Systems, catalog number RTA00); and IL-1 $\beta$-Rat IL-1 beta/IL-1F2 Quantikine ELISA Kit (R\&D Systems, catalog number DY501). The absorbance was measured at $450 \mathrm{~nm}$. IL- $1 \beta$ and TNF- $\alpha$ concentrations were expressed as $\mathrm{pg} / \mathrm{mL}$.

\section{Statistical analysis}

The data are presented as the mean \pm SEM or medians where appropriate. Differences between means were compared using one-way ANOVA followed by the Bonferroni test. The KruskalWallis test followed by Dunn's test was used to compare medians. A value of $p<0.05$ indicated significant differences.
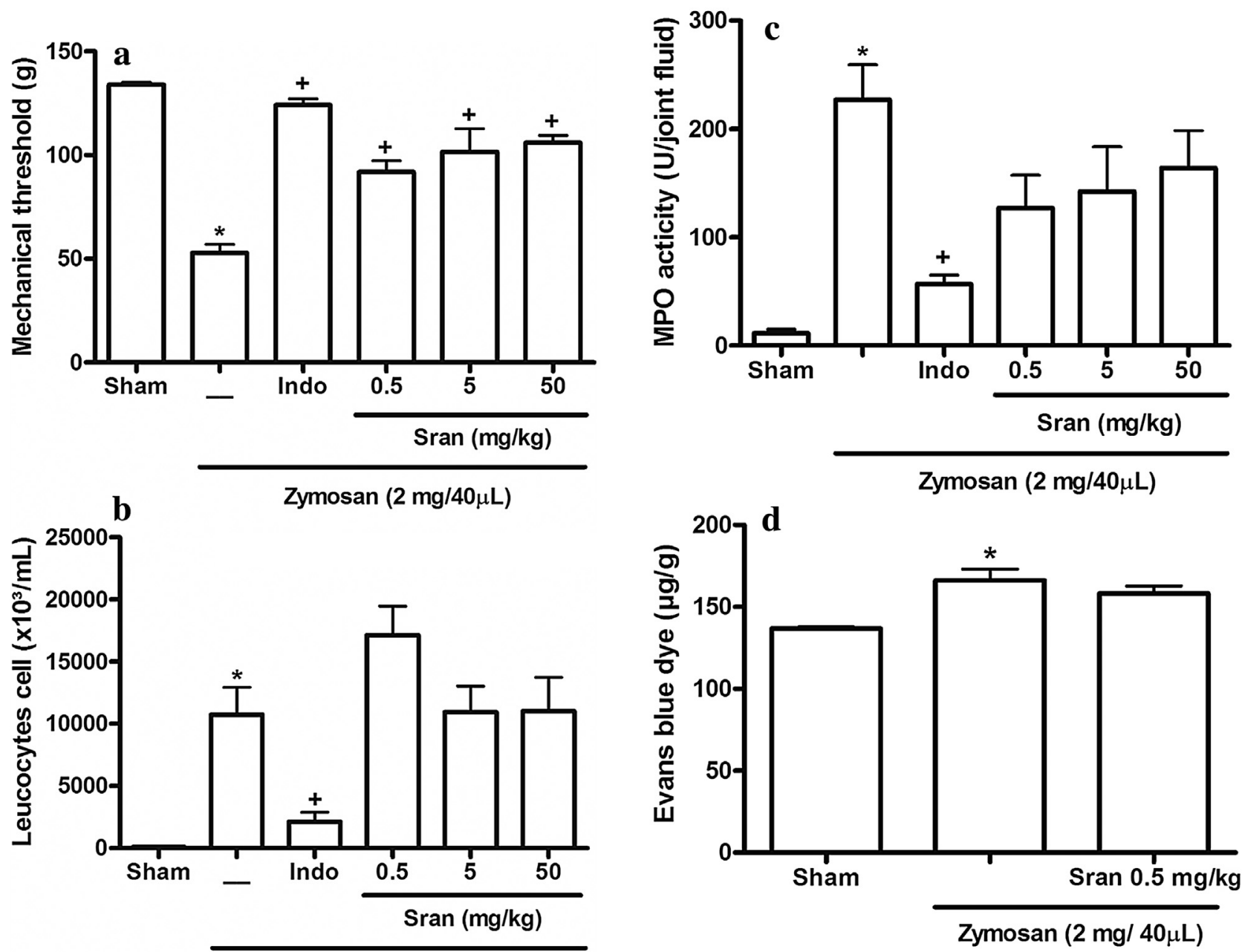

Zymosan (2 mg/40 $\mu \mathrm{L})$

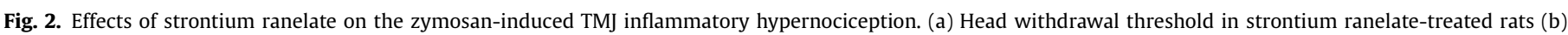

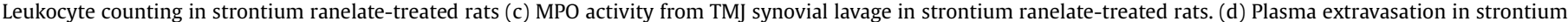

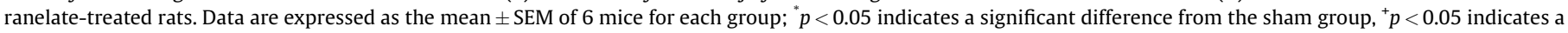
significant difference from the zymosan group (ANOVA, Bonferroni). 


\section{Results}

Effects of strontium ranelate on the zymosan-induced inflammatory hypernociception (Fig. 2)

The intra-articular injection of zymosan caused inflammatory hypernociception that is observed as a decrease in the mechanical threshold of head withdrawal (Fig. 2a). It resulted in a significant increase in the number of polymorphonuclear cells (Fig. 2b) which in turn was certified by the increase of MPO activity in the TMJ synovial lavage after zymosan injection (Fig. 2c). These changes were followed by plasma extravasation into the TMJ after $6 \mathrm{~h}$ (Fig. 2d). Sham animals showed no significant changes in withdrawal threshold, polymorphonuclear cells count, and MPO activity (Fig. 2 a, b, c). Strontium ranelate $(0.5,5$ or $50 \mathrm{mg} / \mathrm{kg}$ ) injected (per os) $1 \mathrm{~h}$ prior to zymosan injection significantly $(p<0.05)$ increased the nociceptive threshold (Fig. 2a). However, strontium ranelate failed to decrease the number of polymorphonuclear cells (Fig. 2b), MPO activity (Fig. 2c), and Evans blue dye extravasation in the synovial lavage (Fig. 2d).

Effects of zinc protoporphyrin IX (ZnPP IX) on the strontium ranelate efficacy (Fig. 3)

To investigate the role of HO- 1 activity in the antinociceptive effect of strontium ranelate, the animals were pre-treated with ZnPP IX ( $3 \mathrm{mg} / \mathrm{kg} ; s c)$, a specific HO-1 inhibitor. The effects of strontium ranelate $(0.5 \mathrm{mg} / \mathrm{kg})$ on the zymosan-induced inflammatory hypernociception (Fig. 3 ) were not changed in the presence of ZnPP-IX (3 mg/kg).

Joint tissue and trigeminal ganglion TNF- $\alpha$ and IL-1 $\beta$ ELISA assays (Fig. 4)

The intra-articular injection of zymosan resulted in a significant increase in TNF- $\alpha$ (Fig. $4 \mathrm{a}$ and $4 \mathrm{~b}$ ) and IL-1 $\beta$ (Fig. 4c and d) levels in both joint tissue and trigeminal ganglion after. Albeit strontium ranelate treatment was not able to significantly reduce IL-1 $\beta$ levels when compared with the zymosan group (Fig. 4c and 4d),

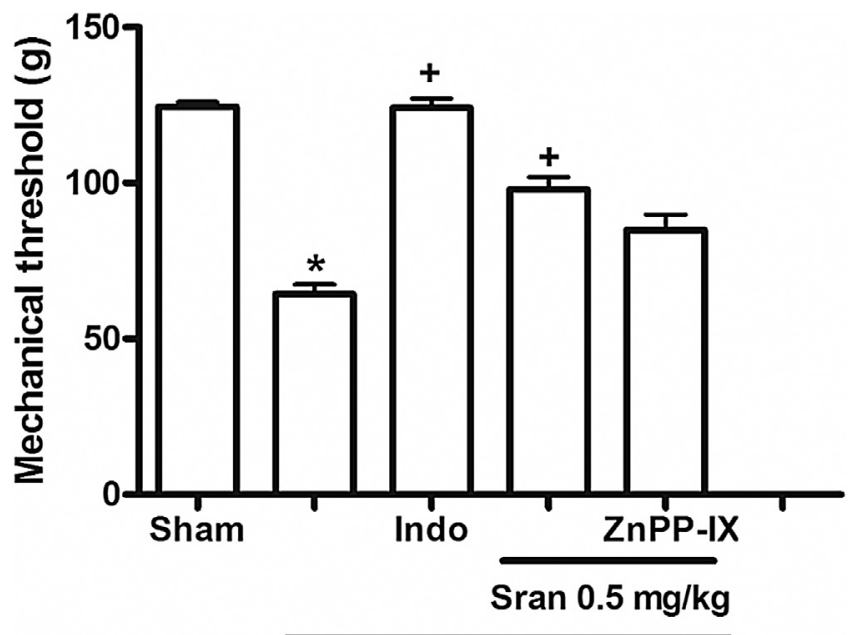

Zymosan (2 mg/40 $\mu \mathrm{L})$

Fig. 3. Effect of zinc protoporphyrin IX (ZnPP IX), a specific HO-1 inhibitor, on the strontium ranelate efficacy on zymosan-induced TMJ inflammatory hypernociception. Data are expressed as the mean \pm SEM of 6 rats for each group; " $p<0.05$ indicates a significant difference from the sham group, ${ }^{+} p<0.05$ indicates a significant difference from the zymosan group (ANOVA, Bonferroni). strontium ranelate reduced TNF- $\alpha$ levels in both joint tissue and trigeminal ganglion (Fig. 4a and 4b).

Histopathological analysis (Fig. 5)

Inflammatory cell influx was observed into the synovial membrane (Fig. 5b) $6 \mathrm{~h}$ after zymosan-injection compared with the sham group (Fig. 5a). The predominant cell types were neutrophils, which characterized acute inflammation. Edema was also observed in the synovium (Fig. 5b). Table 1 shows the scores attributed to TMJ histopathological analysis and compares the values between the sham and zymosan groups. A significant $(p<0.05)$ increase in the inflammatory parameters was observed in the zymosan group. Table 1 also shows the scores attributed to the TMJ histopathological analysis and compares the values between the zymosan and strontium ranelate $(0.5,5$ or $50 \mathrm{mg} /$ $\mathrm{kg}$ ) groups. Strontium ranelate $(0.5,5$ or $50 \mathrm{mg} / \mathrm{kg})$ did not reduce the inflammatory parameters. Figs. $5 \mathrm{c}$ and $5 \mathrm{~d}$ show the TMJ of rats pre-treated with strontium ranelate $(0.5 \mathrm{mg} / \mathrm{kg}$, per os $)$.

Immunohistochemical analysis (Fig. 6)

The immunohistochemical analysis of TNF- $\alpha$ and IL- $1 \beta$ showed increased immunolabeling for both TNF- $\alpha$ and IL-1 $\beta$ in synoviocytes and neutrophlis after zymosan challenge that was characterized by brown-colored cells in the synovial membrane (Fig. 6). The synovial cells in the synovial membrane of the zymosan and strontium ranelate-treated animals also showed both TNF- $\alpha$ and IL-1 $\beta$ expression (Fig. 6). However, in the conjunctive tissue, strontium ranelate $(0.5 \mathrm{mg} / \mathrm{kg})$ treatment reduced TNF- $\alpha$ expression. The negative control group sections consisted of zymosaninduced TMJ inflammatory hypernociception that were not treated with anti-TNF- $\alpha$ or anti-IL-1 $\beta$ antibody. None of the negative controls showed TNF- $\alpha$ or IL- $1 \beta$ immunoreactivity.

\section{Discussion}

We demonstrated that the effects of strontium ranelate on the zymosan-induced TMJ inflammatory hypernociception in rats may occur via TNF- $\alpha$ suppression as well as its mechanism of action in this disease model is IL-1 $\beta / \mathrm{HO}-1$ independent. Experimental animal models of TMJ inflammatory hypernociception have been used to study inflammatory conditions and we performed the first demonstration of TMJ arthritis induced by zymosan, through which we showed that zymosan caused a time-dependent leucocyte migration, plasma extravasation, mechanical hypernociception, and neutrophil accumulation [1]. This shows that the zymosan-induced TMJ arthritis is a reproducible experimental model that can be used to explore the mechanisms underlying TMJ inflammation and potential therapies.

Strontium ranelate was originally designed to treat osteoporosis [17-21], but it may exert effects on osteoarthritis and it has led to positive outcomes in a phase III clinical study [13,22]. Albeit the mechanism of action of strontium ranelate is not fully understood, it appears to stimulate the differentiation of osteoblasts by eliciting the calcium sensor receptor, inhibiting osteoclast differentiation by inhibiting RANKL production, and increasing osteoprotegerin (OPG) activity $[23,24]$.

In addition, patients treated with strontium ranelate had a greater reduction in the total score and pain subscore compared with the placebo group [25]. Since osteoporosis and osteoarthritis are associated with a variety of symptoms, including pain, it could be hypothesized that strontium ranelate may also be effective in reducing the temporomandibular joint inflammatory hypernociception. Our results demonstrated that the intra-articular zymosan injection diminished the mechanical nociceptive threshold, which 


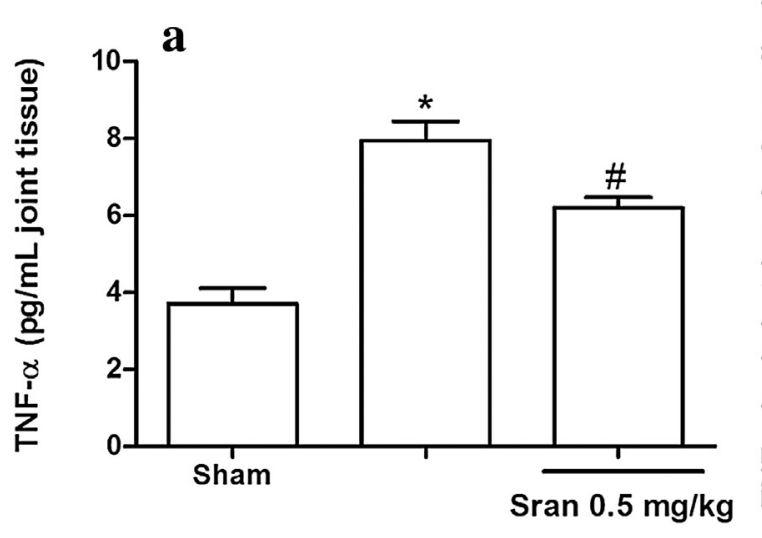

Zymosan (2 $\mathrm{mg} / 40 \mu \mathrm{L})$
음

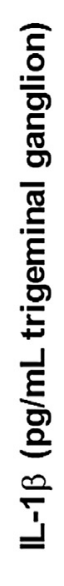

Zymosan (2 mg/40 $\mu \mathrm{L})$

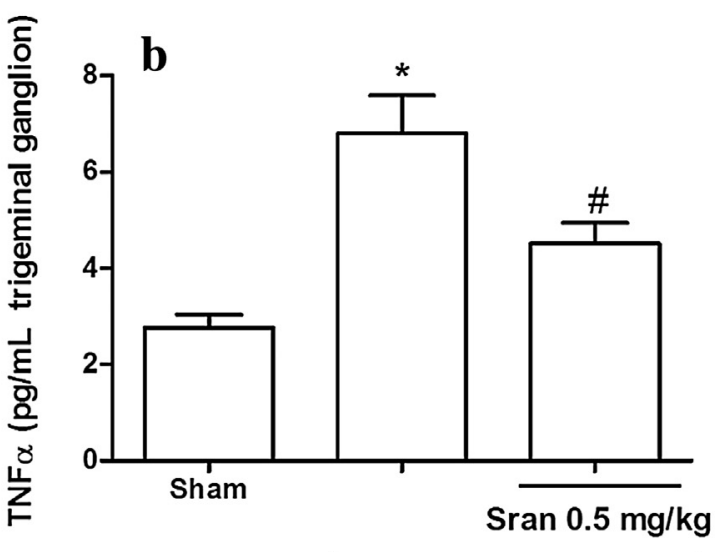

Zymosan (2 mg/40 $\mu \mathrm{L})$

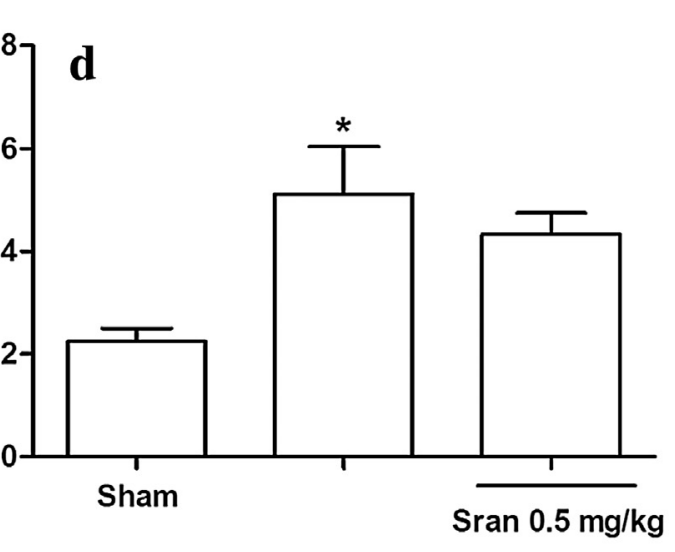

Zymosan $(2 \mathrm{mg} / 40 \mu \mathrm{L})$

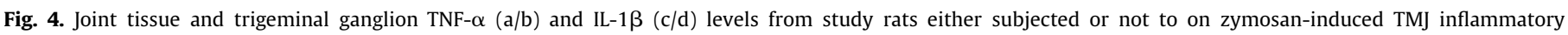

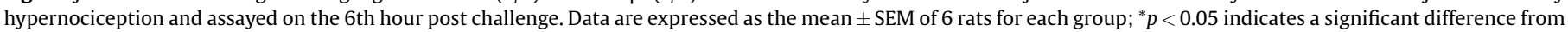
the sham group (ANOVA, Bonferroni).

in turn was increased by the strontium ranelate treatment. However, the inflammatory parameters - cell influx and MPO activity - were not reduced after strontium ranelate treatment. Evans blue extravasation measurement into the synovial lavage did not change following the drug administration. The TMJ histopathological analysis after zymosan injection showed inflammatory cell influx into the synovial membrane, periarticular tissue, and musculoskeletal tissue associated with thickness of synovial membrane, being the drug treatment unable to reverse these findings to a normal status. Likewise, it was demonstrated that strontium ranelate treatment had no particular effect on synovitis in dogs [13].

Studies correlate the HO-1 activity with oxidative damage inhibition and reduction in proinflammatory cytokines production [7]. It was reported that this enzyme had antinociceptive effects on acetic acid-evoked nociception and positive outcomes after induction of HO-1 in a zymosan-induced air pouch inflammation model $[8,26]$. Considering these data, we evaluated the involvement of $\mathrm{HO}-1$ in the strontium ranelate antinociceptive effects and we observed that they were not changed after the pre-treatment with ZnPP-IX, suggesting that HO-1 activity is not involved in its antinociceptive effects.

Many cell types produce cytokines in response to a variety of stimuli, which is a link between cellular injury and the development of local signs and symptoms of inflammation. There is a cascade of release of cytokines linking injuries and the release of nociceptive mediators in rats: a concept that allows us to understand why the inhibition of cytokines causes analgesia [27]. Many studies have demonstrated the contribution of TNF- $\alpha$ to inflammatory hyperalgesia and the clinical success of the anti-TNF$\alpha$ therapy of rheumatoid arthritis also exemplifies this concept $[4,28]$. During the inflammatory response, TNF- $\alpha$ is the first released cytokine and IL-1 $\beta$ is a potent pleiotropic mediator involved in inflammatory responses [29]. Hence, TNF- $\alpha$ and IL-1 $\beta$ are recognized contributors to the pathogenesis of joint diseases, leading to synovial fibroblast hyperplasia and to the destruction of the extracellular matrix [30,31].

In the present study, the zymosan injection resulted in a significant increase in both TNF- $\alpha$ and IL- $1 \beta$ levels so that our findings are in accordance with other ones, suggesting that TNF- $\alpha$ is as driving cytokine of the nociceptive process. TNF- $\alpha$ plays a crucial role in the development of inflammatory hyperalgesia during the inflammatory response in rats, being highly expressed in the synovial fluid of patients with TMJ disorders [5-7]. Additionally, we also demonstrated that treatment with strontium ranelate reduced TNF- $\alpha$ levels in both joint tissue and trigeminal ganglion.

TNF- $\alpha$ is the first cytokine released during an inflammatory response, triggering the release of IL- $1 \beta$ known to activate inflammatory and degradative pathways in synovial cells. Studies suggested high IL-1 $\beta$ levels in the synovial fluid of patients suffering from TMJ disorders [5,29,32]. Nunes et al. [14] 
A

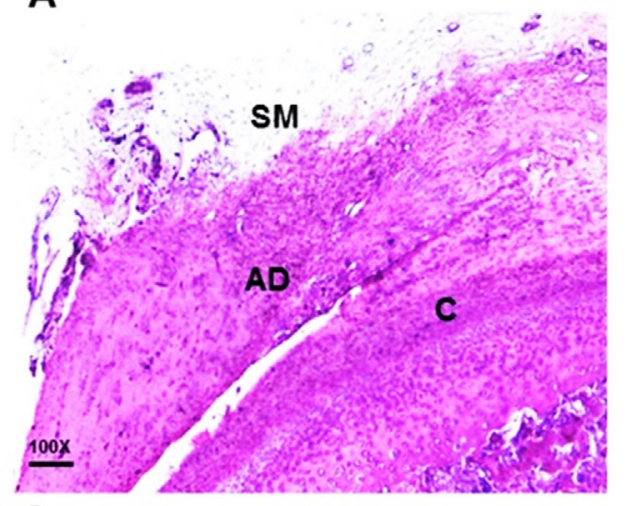

C

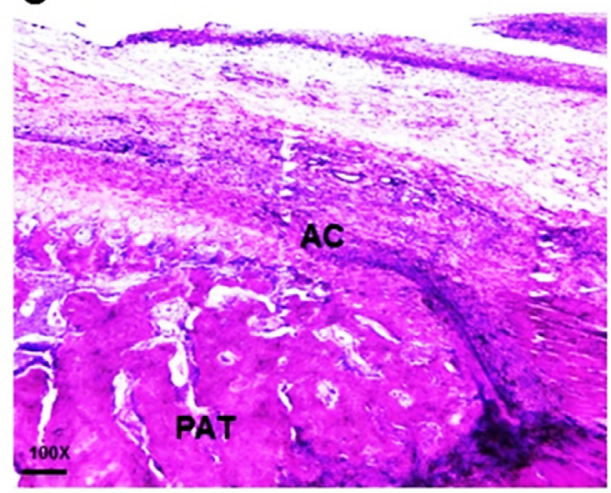

B

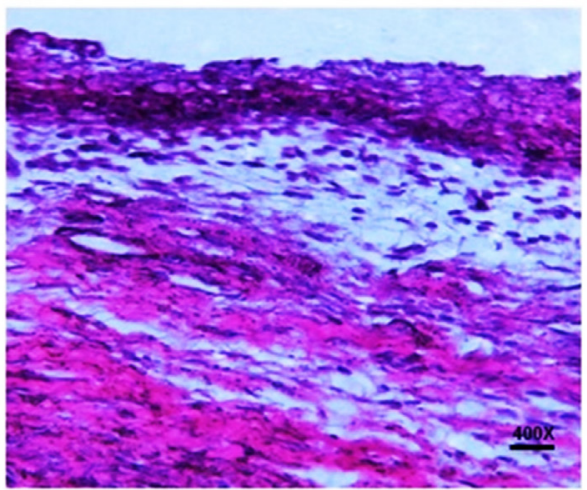

D

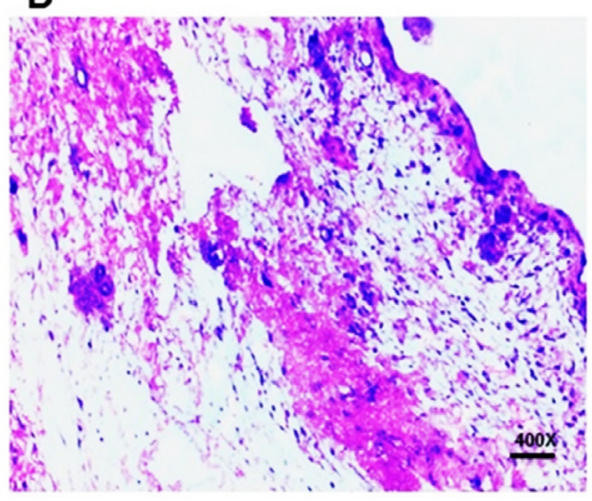

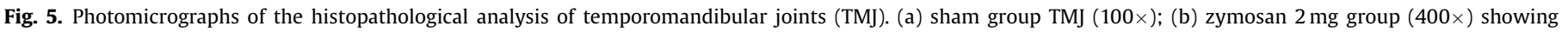

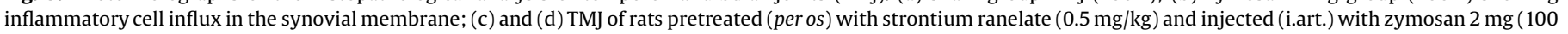

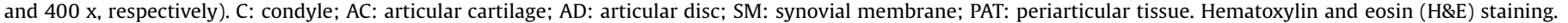

Table 1

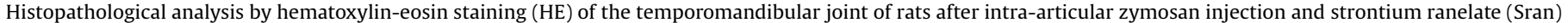
treatment.

\begin{tabular}{|c|c|c|c|}
\hline Groups & $\begin{array}{l}\text { Cell influx in the } \\
\text { synovial membrane }\end{array}$ & Periarticular cell influx & $\begin{array}{l}\text { Cell influx in the } \\
\text { Muscular tissue }\end{array}$ \\
\hline Sham & $1(0-1)$ & $1(0-2)$ & $0(0-0)$ \\
\hline $\mathrm{Zy}$ & $4(2-4)^{*}$ & $3(3-4)^{*}$ & $2.5(2-4)^{*}$ \\
\hline Indo & $2(1-2)^{* *}$ & $2(1-2)^{* *}$ & $1.5(1-2)^{* * *}$ \\
\hline Sran 0.5 & $3.5(2-4)$ & $3.5(3-4)$ & $3.5(2-4)$ \\
\hline Sran 5 & $3(2-3)$ & $3.5(3-4)$ & $3.5(2-4)$ \\
\hline Sran 50 & $3(2-4)$ & $4(2-4)$ & $4(2-4)$ \\
\hline
\end{tabular}

${ }^{*} p<0.05$ versus Sham; ${ }^{* *} p<0.05$ versus Zymosan (Kruskal-Wallis, Dunn's).

investigated the anti-inflammatory activity of strontium ranelate in the articular incapacitation test, in the paw-pressure test, and in the anterior cruciate ligament transection model. Unlike our protocol, the animals received strontium ranelate at higher doses: $30-300 \mathrm{mg} / \mathrm{kg}$ per os. They find that strontium ranelate dosedependently inhibited joint pain in both types of arthritis models, but it did not alter cell influx which is a similar result obtained here. Contrary to them, our findings suggest that the strontium ranelate treatment is not capable of reducing IL-1 $\beta$ levels compared with the zymosan group.

This might be related to the differences in the design performed by Nunes et al. [14]. The strontium ranelate dose administered in their protocol is far higher than the one we used, which could potentiate the analgesic effects of this drug. Other essential difference is the experimental model of diseases that could culminate in distinct results as different disease models may imply in contrasting pathogenesis mechanisms, thus, leading to different results. As pointed out by Nunes et al. [14], naloxone abolished the strontium ranelate analgesic effect which is valuable information on the strontium ranelate unspecific mechanism of action.

Furthermore, the immunohistochemical analysis showed increased TNF- $\alpha$ and IL-1 $\beta$ immunolabeling in the synovial cells after the intra-articular zymosan injection. Albeit strontium ranelate slightly reduced the TNF- $\alpha$ immunolabeling in the conjunctive tissue, it was not able to diminish the IL-1 $\beta$ immunolabeling one. Contrary to this result, in the synovial membrane of dogs undergoing sectioning of the anterior cruciate ligament, the genetic expression of IL- $1 \beta$ was significantly reduced by strontium ranelate treatment at the doses of 50 or $75 \mathrm{mg} / \mathrm{kg}$ per day for 16 weeks [13]. A possible explanation for these 
Control

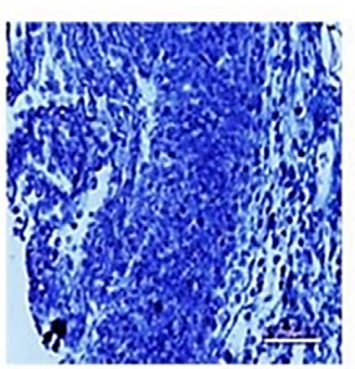

IL1及

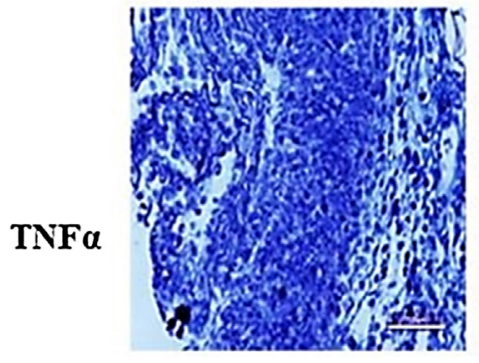

Sham
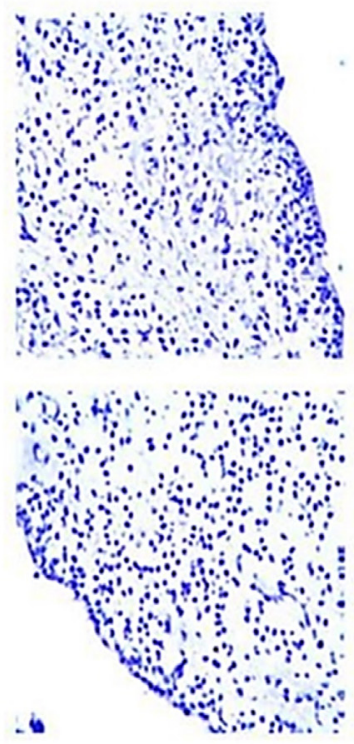

Zymosan

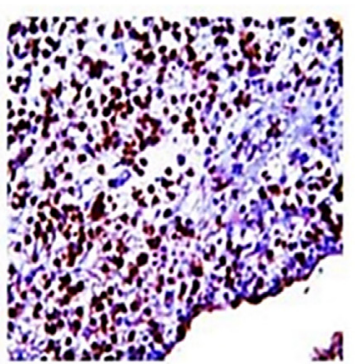

$\Delta$

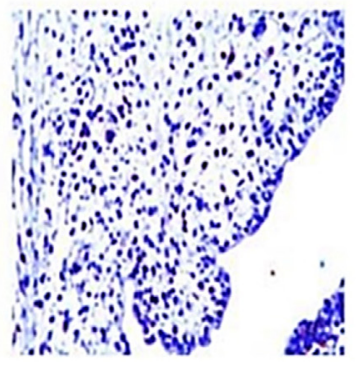

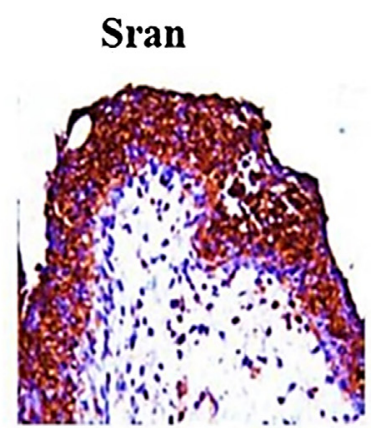

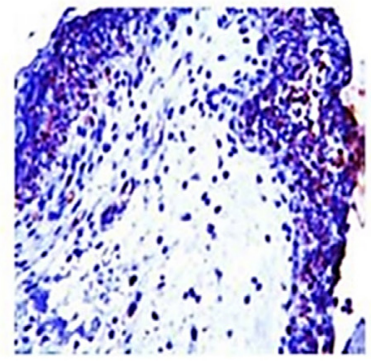

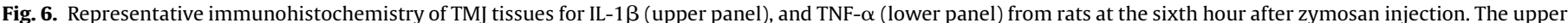

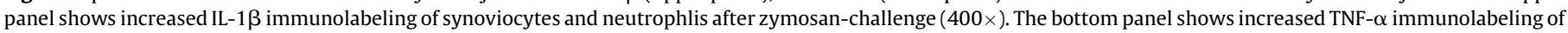

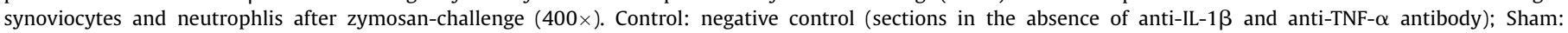
unchallenged rats; Zymosan: zymosan-challenged rats receiving $0.9 \%$ saline solution; Sran 0.5: zymosan-challenged rats receiving strontium ranelate (0.5 mg/kg).

contradictory results could be the different animal model of disease along with the adopted posology, leading to contradictory results from what we obtained.

Therefore, albeit the mechanisms of action through which strontium ranelate exerts antinociceptive effects remain relatively elusive, this study provides novel information on its effects on the zymosan-induced TMJ inflammatory hypernociception as strontium ranelate primarily suppressed TNF- $\alpha$ levels and reduced the nociceptive threshold. The inflammatory stimuli or tissue injuries stimulate the release of characteristic cytokine cascades, which ultimately trigger the release of final mediators responsible for inflammatory pain. These final mediators, such as prostanoids or sympathetic amines, act directly on the nociceptors to cause hypernociception, which results from the lowering of threshold due to modulation of specific voltage-dependent sodium channels.

As reported here, strontium ranelate could decrease hypernociception thresholds by reducing TNF- $\alpha$ levels in the periarticular tissues and trigeminal ganglion. Given the importance of these structures to the temporomandibular joint pain onset and progression, we suggest that TNF- $\alpha$ functions as a target point for strontium ranelate. This suggests that strontium ranelate might be a potential candidate for the treatment of TMJ pain through TNF- $\alpha$ inhibition and more studies of longer duration are necessary to validate the use of strontium ranelate in the pain management.

\section{Conflict of interests}

The authors declare that they have no conflict of interest regarding the publication of this study.

\section{Funding}

This work was supported by Brazilian grants from Fundação Cearense de Apoio ao Desenvolvimento Científico e Tecnológico (FUNCAP), Conselho Nacional de Desenvolvimento Científico e Tecnológico (CNPq), Coordenação de Aperfeiçoamento de Pessoal de Nível Superior (CAPES), and Instituto de Biomedicina do SemiÁrido Brasileiro (INCT).

\section{Acknowledgment}

The authors thank Adalberto Nascimento de Lima Júnior for technical assistance.

\section{References}

[1] Chaves HV, Ribeiro RA, Souza AM, Silva AAR, Gomes AS, Vale ML, et al. Experimental model of zymosan-induced arthritis in the rat temporomandibular joint: role of nitric oxide and neutrophils. J Biomed Biotechnol 2011;200:1-2011.

[2] Bezerra MM, Brain SD, Girão VCC, Greenacre S, Keeble J, Rocha FAC. Neutrophils-derived peroxynitrite contributes to acute hyperalgesia and cell influx in zymosan arthritis. Naunyn Schmiedebergs Arch Pharmacol 2007:374:265-73.

[3] Gegout P, Gillet P, Chevrier D, Guingamp C, Terlain B, Netter P. Characterization of zymosan-induced arthritis in the rat: effects on joint inflammation and cartilage metabolism. Life Sci 1994;55:321-6.

[4] Cunha FQ, Poole S, Lorenzetti BB, Ferreira SH. The pivotal role of tumour necrosis factor alpha in the development of inflammatory hyperalgesia. $\mathrm{Br} \mathrm{J}$ Pharmacol 1992;107:660-4.

[5] Akutsu M, Ogura N, Ito K, Kawashima M, Kishida T, Kondoh T. Effects of interleukin-1 $\beta$ and tumor necrosis factor- $\alpha$ on macrophage inflammatory protein-31 production in synovial fibroblast-like cells from human temporomandibular joints. J Oral Pathol Med 2013;42:491-8.

[6] Gulen H, Ataoglu H, Haliloglu S, Isik K. Proinflammatory cytokines in temporomandibular joint synovial fluid before and after arthrocentesis. Oral Surg Oral Med Oral Pathol Oral Radiol Endod 2009;107:1-4.

[7] Alcaraz MJ, Fernández P, Guillén MI. Anti-inflammatory actions of the heme oxygenase-a pathway. Curr Pharm Des 2003;9:2541-51.

[8] Grangeiro NMG, Aguiar JA, Chaves HV, Silva AAR, Lima V, Benevides NMB, et al. Heme oxygenase/carbon monoxide-biliverdin pathway may be involved in the antinociceptive activity of etoricoxib, a selective COX-2 inhibitor. Pharmacol Rep 2011;63:112-9.

[9] Vanderlei ESO, Araújo IWF, Quinderé ALG, Pontes BP, Eloy YRG, Rodrigues JAG, et al. The involvement of the HO-1 pathway in the anti-inflammatory action of a sulfated polysaccharide isolated from the red seaweed Gracilaria birdiae. Inflamm Res 2011;60:1121-30.

[10] Cianferotti L, D'Asta F, Brandi LM. A review on strontium ranelate long-term antifracture efficacy in the treatment of postmenopausal osteoporosis. Her Adv Musculoskel Dis 2013;0:1-13.

[11] Reginster J, Badurski J, Bellamy N, Bensen W, Chapurlat R, Chevalier X. Efficacy and safety of strontium ranelate in the treatment of knee osteoarthritis: 
results of a double-blind, randomised, placebo-controlled trial. Ann Rheum Dis 2013;72:179-86.

[12] Karsdal MA, Bay-Jensen AC, Lories RJ, Abramson S, Spector T, Pastoureau P, et al. The coupling of bone and cartilage turnover in osteoarthritis: opportunities for bone antiresorptives and anabolics as potential treatments? Ann Rheum Dis 2014;73(2):336-48.

[13] Pelletier JP, Kapoor M, Fahmi H. Strontium ranelate reduces the progression of experimental dog osteoarthritis by inhibiting the expression of key proteases in cartilage and of IL-1beta in the synovium. Ann Rheum Dis 2013;72:250-7.

[14] Nunes RM, Martins MR, Silva Junior FS, Melo Leite AC, Girão VC, Cunha FQ et al. Strontium ranelate analgesia in arthritis models is associated to decreased cytokine release and opioid-dependent mechanisms. Inflamm Res 2015;64:781-7.

[15] Denadai-Souza A, Camargo L, de L, Ribela MT, Keeble JE, Costa SK, et al. Participation of peripheral tachykinin NK receptors in the carrageenan induced inflammation of the rat temporomandibular joint. Eur J Pain 2010;13:812-9.

[16] Kwan CL, Hu JW, Sessle BJ. Neuroplastic effects of neonatal capsaicin on neurons in adult rat trigeminal nucleus principalis and subnucleus oralis. J Neurophysiol 1996;75:210-98.

[17] Ammann P, Shen V, Robin B, Mauras Y, Bonjour JP, Rizzoli R. Strontium ranelate improves bone resistance by increasing bone mass and improving architecture in intact female rats. J Bone Miner Res 2004;19:2012-20.

[18] Buehler J, Chappuis P, Saffar JL, Tsouderos Y, Vignery A. Strontium ranelate inhibits bone resorption while maintaining bone formation in alveolar bone in monkeys. Bone 2001;29:176-9.

[19] Delannoy P, Bazot D, Marie P. Long-term treatment with strontium ranelate increases vertebral bone mass without deleterious effect in mice. Metabolism 2002;51:906-11.

[20] Park SY, Kim YH, Kim EK, Ryu EY, Lee SJ. Heme oxygenase-a signals are involved in preferential inhibition of pro-inflammatory cytokine release by surfactin in cells activated with porphyromonas gingivalis lipopolysaccharide. Chem Biol Interact 2010;3:437-45.
[21] Reginster J, Deroisy R, Neuprez A, Hiligsmann A, Zegels B, Bruyere O. Strontium ranelate: new data on fracture prevention and mechanisms of action. Cur Osteoporos Rep 2009; 7:96-102.

[22] Alexandersen P, Karsdal MA, Qvist P. Strontium ranelate reduces the urinarylevel of cartilage degradation biomarker CTX-II in postmenopausal women. Bone 2007;40:218-22.

[23] Atkins GJ, Welldon KJ, Halbout P. Strontium ranelate treatment of human primary osteoblasts promotes an osteocyte-like phenotype while eliciting an osteoprotegerin response. Osteoporos Int 2009;20:653-64.

[24] Coulombe J, Faure H, Robin B. In vitro effects of strontium ranelate on the extracellular calcium-sensing receptor. Biochem Biophys Res Commun 2004;323:1184-90.

[25] Bruyere O, Delferriere D, Roux C. Effects of strontium ranelate on spinal osteoarthritis progression. Ann Rheum Dis 2008;67:335-9.

[26] Vicente AM, Guillen MI, Habib A, Alcaraz MJ. Beneficial effects of heme oxygenase-a up-regulation in the de velopment of experimental inflammation induced by zymosan. J Pharmacol Exp Ther 2003;307:1030-7.

[27] Cunha TM, Verri WA. Jr Silva JS, Poole S, Cunha FQ: A cascade of cytokines mediates mechanical inflammatory hyperalgesia in mice. Proc Natl Acad Sci U S A 2005;102(5):1755-60.

[28] Rankin EC, Choy EH, Kassimos D, Kingsley GH, Sopwith AM, Insenberg DA, et al The therapeutic effects of an engineered human anti-tumour necrosis factor alpha antibody (CDP571) in rheumatoid arthritis. Rheumatol 1995;34:334-42.

[29] Cunha TM, Verri WA, Silva Jr JS, Poole S, Cunha FQ. A cascade of cytokines mediates mechanical inflammatory hyperalgesia in mice. Proc Natl Acad Sci U S A 2005;102(5):1755-60.

[30] Kay J, Calabrese L. The role of interleukin-a in the pathogenesis of rheumatoid arthritis. Rheumatology 2004;43:2-9.

[31] Field M. Tumour necrosis factor polymorphisms in rheumatic diseases. Q J Med 2001;94:237-46.

[32] Kubota E, Kubota T, Matsumoto J, Shibata T, Murakami K. Synovial fluid cytokines and proteinases as markers of temporomandibular joint disease. J Oral Maxillofac Surg 1998;56:192-8. 